Communications in Physics, Vol. 26, No. 3 (2016), pp. 241-246

DOI:10.15625/0868-3166/26/3/9023

\title{
SYNTHESIS OF FLOWER-LIKE SILVER NANOSTRUCTURES ON SILICON AND THEIR APPLICATION IN SURFACE-ENHANCED RAMAN SCATTERING
}

\author{
KIEU NGOC MINH ${ }^{1, \dagger}$, CAO TUAN ANH ${ }^{2}$, LUONG TRUC QUYNH NGAN ${ }^{1}$, LE VAN VU ${ }^{3}$ \\ AND DAO TRAN CAO ${ }^{1}$ \\ ${ }^{1}$ Institute of Materials Science, Vietnam Academy of Science and Technology, \\ 18 Hoang Quoc Viet, Cau Giay, Hanoi, Vietnam \\ ${ }^{2}$ Tan Trao University, Trung Mon Commune, Yen Son District, Tuyen Quang Province, Vietnam \\ ${ }^{3}$ VNU University of Science, Vietnam National University, Hanoi, \\ 334 Nguyen Trai, Thanh Xuan, Hanoi, Vietnam \\ ${ }^{\dagger}$ E-mail: kieungocminhcdvp@gmail.com
}

Received 30 September 2016

Accepted for publication 20 November 2016

\begin{abstract}
To enhance the intensity of surface-enhanced Raman scattering (SERS), production of metal nanostructures with sharp points, lying side by side at the nanometer level plays an extremely important role. In this paper, we report on a manufacturing process in which the silver nanoparticles with flower-like shape have been fabricated by chemical deposition of silver particles on silicon wafers, using a solution of hydrofluoric acid $(\mathrm{HF})$, silver nitrate $\left(\mathrm{AgNO}_{3}\right)$ and ascorbic acid (AsA) in water, at room temperature. We found that only when the concentrations of $\mathrm{AgNO}_{3}$ and $\mathrm{AsA}$ are appropriate, the flower-like silver nanoparticles will form. Note that while other authors mainly manufactured flower-like silver nanoparticles in the form of suspensions, we have created flower-like silver nanoparticles with cabbage-shape on a silicon surface. These ensembles of flower-like silver nanoparticles were used as SERS substrates to detect crystal violet $(\mathrm{CV})$ in low concentrations.
\end{abstract}

Keywords: SERS, silver, nanoflower, crystal violet.

Classification numbers: 33.20Fb, 73.20.Mf, 81.07.-b, 81.16.Be.

(C)2016 Vietnam Academy of Science and Technology 


\section{INTRODUCTION}

It is well known that Raman scattering is a valuable tool to identify chemical and biological samples via determination of the characteristic oscillations of the molecules contained in the sample. Since the discovery of surface-enhanced Raman scattering (SERS), an important issue is to successfully fabricate SERS substrates with high stability, good repeatability as well as provides greater Raman enhancement factor. However, in normal conditions Raman scattering probability is very small, so the ability for identifying molecules of a substance based on Raman scattering only really become significant since the discovery of surface-enhanced Raman scattering (SERS). It is known that there are two mechanisms for SERS enhancement. One of them is the chemical enhancement [1]. The remaining is an enhancement of the local electromagnetic field, which is derived from plasmon excitations on metallic surfaces [2-4]. Deposition of the precious metal particles on a surface is not complicated and expensive. This is the method commonly used for deposition of precious metals such as gold $(\mathrm{Au})$ or silver $(\mathrm{Ag})$ onto the metal or semiconductor (such as $\mathrm{Sn}, \mathrm{Zn}, \mathrm{Cu}, \mathrm{Si}$ and $\mathrm{Ge}$ ) surface [5-7]. On the other hand, deposition of precious metal particles on the surface of a silicon wafer provides a low-cost and convenient path to produce SERS substrate, without adding other complex techniques such as collection and re-dispersion of the precious metal particles on a certain surface, as in the case of the production of colloidal particles of precious metals [8]. So far, the precious metal micro- or nano-structures with a flower-like morphology are synthesized primarily in the form of a colloidal solution [9-11]. Some metal flowerlike nanostructures have been successfully fabricated as a layer deposited on the silicon substrate, using polyvinyl pyrrolidone (PVP) or a number of other chemicals as reducing agent [12-14]. Until the present time we have not found any reports related to the manufacture of silver nano-flowers (AgNFs) on silicon surface (AgNFs@Si) using ascorbic acid (AsA) as a reducing agent.

In this report, we present the results of the successful deposition of AgNFs with cabbagelike shape on the surface of a silicon wafer. We have also successfully controlled surface morphology of AgNFs and used them as SERS substrates to detect the traces of crystal violet (CV) until $0.01 \mathrm{ppm}$ concentration.

\section{EXPERIMENT}

AgNFs have been fabricated by the chemical deposition method on the surface of silicon wafers at room temperature. Silicon used is p-type single crystal, orientation (111). Chemicals used include: $\mathrm{AgNO}_{3}$ (98\%), $\mathrm{HF}(40 \%)$, AsA (99.7\%), deionized water. Firstly, a silicon wafer is cut into pieces about $0.6 \times 0.6 \mathrm{~cm}^{2}$ in size, then they are soaked in alcohol, following by nitric acid $\left(\mathrm{HNO}_{3}\right)$ and finally hydrofluoric acid (HF). The work mentioned above will give us the clean silicon samples. In a typical experiment, a solution containing $4.8 \mathrm{M} \mathrm{HF}$ and $1 \mathrm{mM} \mathrm{AgNO} \mathrm{As}_{3}$ was stirred at a speed of $200 \mathrm{rpm}$ for 5 min with the aim of creating a homogeneous solution, then a treated silicon sample is placed in the above solution, simultaneously with the addition of a predetermined amount of prepared AsA solution. The total volume of the solution is $100 \mathrm{ml}$, the concentration of AsA is $5 \mathrm{mM}$. Depending on the reaction time, the reaction solution changes color from gray to white milk. After the fabrication ended, AgNFs@Si sample was taken out from the beaker carefully, then it was washed with deionized water for the purpose of removal of the reactant left on the sample surface. Surface morphology of the AgNFs@Si samples was observed by SEM measurements, using scanning electron microscope S-4800 (Hitachi, Japan). 
SERS spectra were recorded by a Jobin-Yvon LabRam Raman system with the excitation laser wavelength of $632.8 \mathrm{~nm}$, which is located at the University of Natural Sciences, Vietnam National University of Hanoi.

\section{RESULTS AND DISCUSSION}

In the reaction solution, $\mathrm{Ag}^{+}$ions are reduced simultaneously by $\mathrm{HF}$ and AsA to form silver atoms via two following reaction $[5,15-17]$ :

$$
\begin{gathered}
\mathrm{C}_{6} \mathrm{H}_{8} \mathrm{O}_{6}+2 \mathrm{Ag}^{+} \longrightarrow \mathrm{C}_{6} \mathrm{H}_{6} \mathrm{O}_{6}+2 \mathrm{Ag}+2 \mathrm{H}^{+} \\
4 \mathrm{Ag}^{+}(\mathrm{aq})+\mathrm{SiO}(\mathrm{s})+6 \mathrm{~F}(\mathrm{aq}) \longrightarrow 4 \mathrm{Ag}(\mathrm{s})+\mathrm{SiF}_{6}^{2-}(\mathrm{aq})
\end{gathered}
$$

In a series of samples produced, with the reaction solution which consists of only three chemicals, including $\mathrm{AgNO}_{3}, \mathrm{HF}$, and AsA, many forms of silver particles have been created. By changing the experimental parameters such as concentration of $\mathrm{AgNO}_{3}$ and $\mathrm{AsA}$, reaction time, we can adjust and control the morphology of silver particles. As shown in Fig. 1 and Fig. 2, the silver particles produced have a cabbage-like morphology. All silver particles that are deposited onto the same silicon sample are uniform in shape and size. They are created by combining the "unit" silver nanoparticles, which have a much smaller size than the particles shown in Fig. 1. The development process of the silver flower-like structure with time is illustrated by the SEM images shown in Fig. 1 (a), (b), and (c), where the concentration ratio of AsA over $\mathrm{AgNO}_{3}$ was selected as 5:1, and the reaction time is $30 \mathrm{sec}, 5 \mathrm{~min}$ and $10 \mathrm{~min}$, respectively for the Fig. 1 (a), (b) and (c).

As shown in Fig. 1(a), after $30 \mathrm{sec}$ of reaction, the products obtained are the silver nanoflowers with a sparse density. With the increase of reaction time, at first $5 \mathrm{~min}$, then $10 \mathrm{~min}$, flower density is increased many times, as shown in Fig. 1 (b) and (c), respectively. We have changed the concentration of AsA from $5 \mathrm{mM}$ (Fig. 2(a)), up to $7 \mathrm{mM}$ (Fig.2(b)), and then to $10 \mathrm{mM}$ (Fig.2(c)), while keeping unchanged the $\mathrm{AsA}: \mathrm{AgNO}_{3}$ concentration ratio, then silver flower shape changes to the direction in which the surface becomes more uneven. The fabricated silver flower patterns have proven to be relatively uniform in shape and size (about $500 \mathrm{~nm}$ ). Their surfaces show that there are many hot spots which have been formed, the hot spots include the bulge of flowers, the overlapping portion between the flowers lying next to each other, the narrow gap between the branches of the same flower. According to our estimation, the narrow gaps are very small in the size range from several nanometers to several tens of nanometers. Hot spots above play a crucial role in enhancing the Raman signal.

The fabricated silver nanostructures with cabbage-like shape have been used to identify crystal violet $(\mathrm{CV})$, and good SERS signals were obtained as shown in Fig. 3. For each AgNFs@Si sample, an amount of $25 \mu 1$ of aqueous CV with certain concentration was dripping onto the sample. The typical peaks of CV have been obtained, as the bands of 800, 913, 1174, 1375 and $1618 \mathrm{~cm}^{-1}$. These bands are assigned to phenyl-H out-of-plane antisymmetric bending $\left(800 \mathrm{~cm}^{-1}\right)$, phenyl ring breathing mode $\left(913 \mathrm{~cm}^{-1}\right), \mathrm{C}$-phenyl and $\mathrm{C}-\mathrm{H}$ in-plane antisymmetric stretching $\left(1375 \mathrm{~cm}^{-1}\right), \mathrm{C}-\mathrm{N}$ and phenyl-C-phenyl antisymmetric stretching, C-phenyl in-plane antisymmetric stretching $\left(1618 \mathrm{~cm}^{-1}\right)$ [18]. Figure 2 shows that the fabricated AgNFs@Si substrate can identify $\mathrm{CV}$ molecule in concentrations as low as $0.01 \mathrm{ppm}$. 

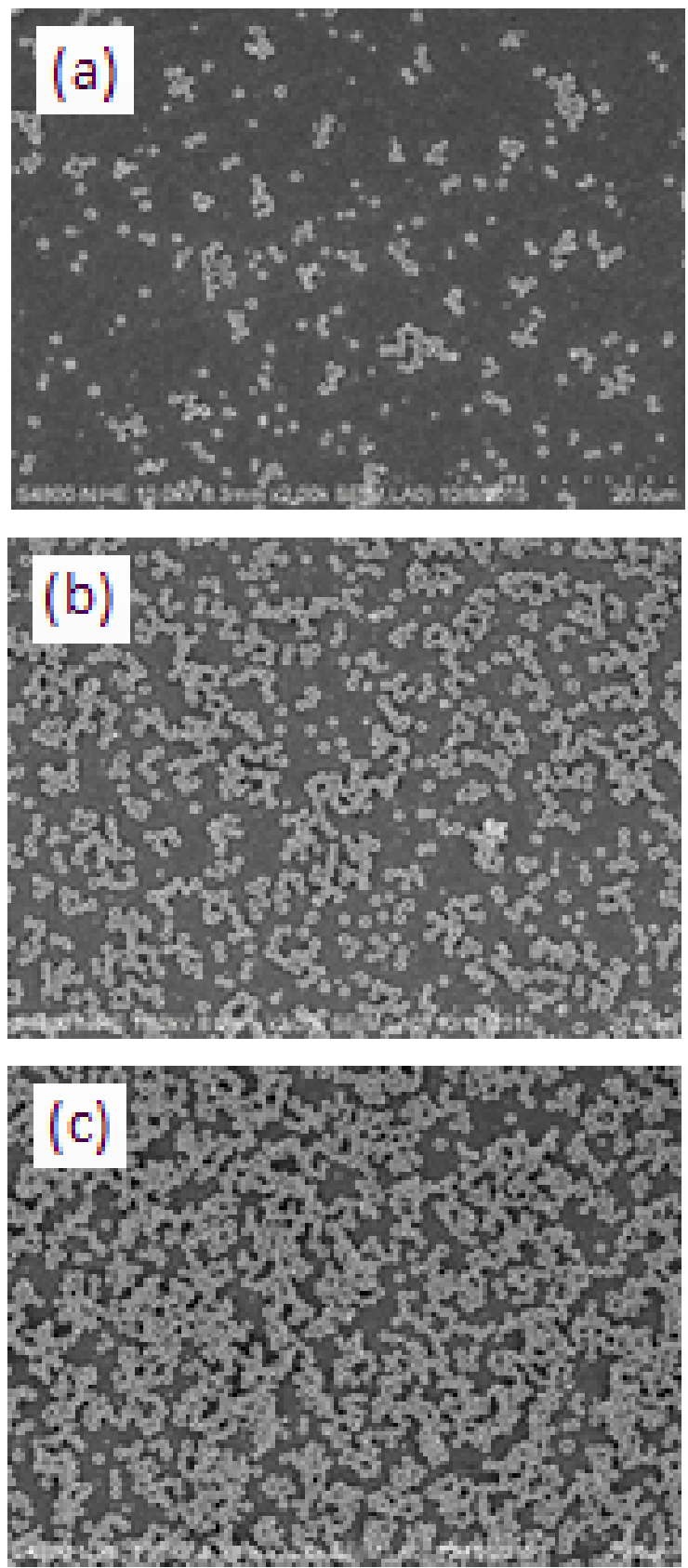

Fig. 1. The dependence of the density of the silver particles (with cabbage-like shape) on chemical deposition time: (a) $30 \mathrm{sec}$, (b) $5 \mathrm{~min}$, and (c) $10 \mathrm{~min}$. Note: the ratio of the concentrations AsA: $\mathrm{AgNO}_{3}$ is 5:1 and the concentration of AsA is $5 \mathrm{mM}$. 

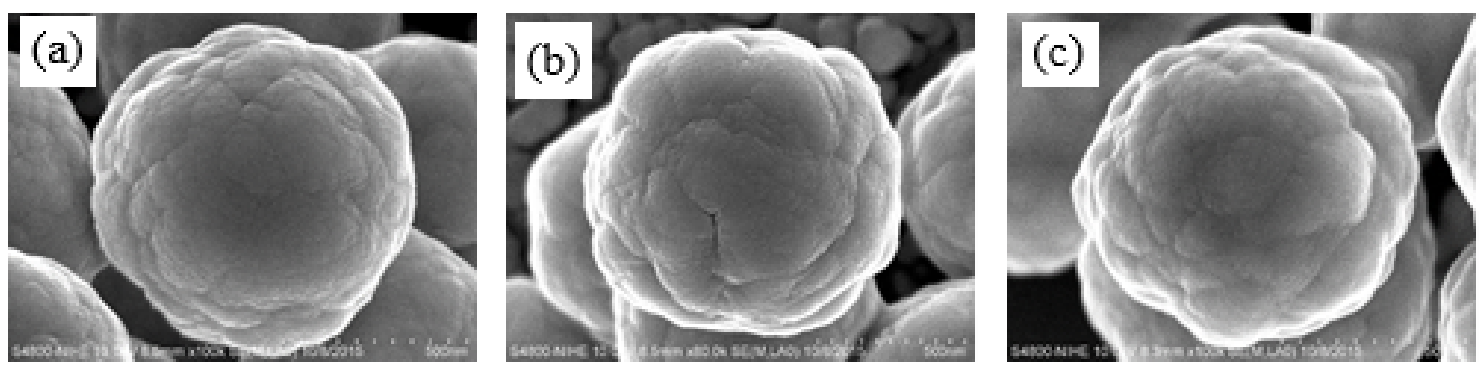

Fig. 2. The dependence of the morphology of the silver particles with cabbage-like shape on the concentration of AsA in chemistry deposition solution: (a) $5 \mathrm{mM}$, (b) $7 \mathrm{mM}$, and (c) $10 \mathrm{mM}$. Note: the ratio of the concentrations $\mathrm{AsA}: \mathrm{AgNO}_{3}$ is 5:1 and the time of deposition is $10 \mathrm{~min}$.

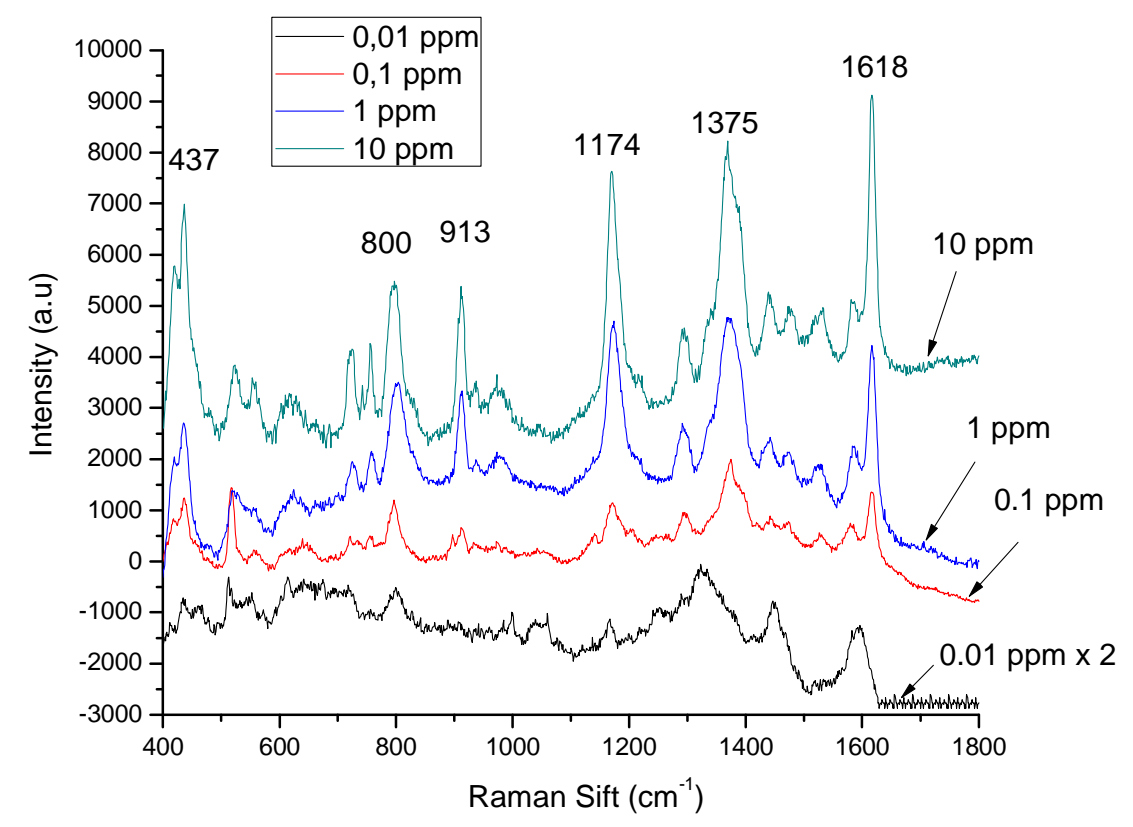

Fig. 3. SERS spectra of crystal violet with various concentrations, which have been obtained by SERS substrates of silver flower with cabbage-like shape.

\section{CONCLUSION}

Our study has successfully produced the silver particles with a cabbage-like shape on a silicon wafer at room temperature, by the chemical deposition method using ascorbic acid (AsA) as the reducing agent. Our study shows that, when using the aforementioned silver flowers as SERS substrates, we could detect the traces of crystal violet (CV) with concentrations as low as $0.01 \mathrm{ppm}$. 


\section{ACKNOWLEDGMENT}

The present research was supported financially by the Vietnam Academy of Science and Technology under project VAST.DLT.04/17-18.

\section{REFERENCES}

[1] H. Cang, A. Labno, C. Lu, X. Yin, M. Liu, C. Gladden, Y. Liu, and X. Zhang, Nature 469 (2011) 385-389.

[2] N. A. Hatab, C.-H. Hsueh, A. L. Gaddis, S. T. Retterer, J.-H. Li, G. Eres, Z. Zhang, and B. Gu, Nano Letters 10 (2010) 4952-4955.

[3] M. Schnell1, A. García-Etxarri, A. J. Huber, K. Crozier, J. Aizpurua, and R. Hillenbrand, Nature Photonics 3 (2009) 287-291.

[4] Z. Li, S. Zhang, N. J. Halas, P. Nordlander, and H. Xu, Small 7 (2011) 593-596.

[5] K. Peng, Y. Yan, S. Gao, and J. Zhu, Advanced Functional Materials 13 (2003) 127-132.

[6] W. Song, Y. Cheng, H. Jia, W. Xu, and B. Zhao, Journal of Colloid and Interface Science 298 (2006) 765-768.

[7] T. C. Dao, T. Q. N. Luong, T. A. Cao, N. M. Kieu, and V. V. Le, Advances in Natural Sciences: Nanoscience and Nanotechnology 7 (2016) 015007 (6pp).

[8] Y. Wang, P. H. C. Camargo, S. E. Skrabalak, H. Gu, and Y. Xia, Langmuir 24 (2008) 12042-12046.

[9] Q. Huang and X. Zhu, Materials Chemistry and Physics 138 (2013) 689-694.

[10] T. T. Nhung, Y. Bu, and S. -W. Lee, Journal of Crystal Growth 373 (2013) 132-137.

[11] L. Cheng, C. Ma, G. Yang, H. You, and J. Fang, Journal of Materials Chemistry A 2 (2014) 4534-4542.

[12] S. Xu, Y. Yao, Z. Li, H. Zhang, F. Huang, and W. Huang, Materials Letters 82 (2012) 202-204.

[13] L. Chen, Q. Jing, J. Chen, B. Wang, J. Huang, and Y. Liu, Materials Characterization 85 (2013) 48-56.

[14] M. Yan, Y. Xiang, L. Liu, L. Chai, X. Lia, and T. Feng, RSC Advances 4 (2014) 98-104.

[15] G. V. Kuznetsov, V. A. Skryshevsky, T. A. Vdovenkova, A. I. Tsyganova, P. Gorostiza, and F. Sanz, Journal of The Electrochemical Society 148 (2001) C528-C532.

[16] K. P. Velikov, G. E. Zegers, and A. van Blaaderen, Langmuir 19 (2003) 1384-1389.

[17] L. Lu, A. Kobayashi, K. Tawa, and Y. Ozaki, Chemistry of Materials 18 (2006) $4894-4901$.

[18] F. A. Harraza, A. A. Ismaila, H. Bouzida, S.A. Al-Sayaria, A. Al-Hajrya, M.S. Al-Assiri, Applied Surface Science 331 (2015) 241-247. 